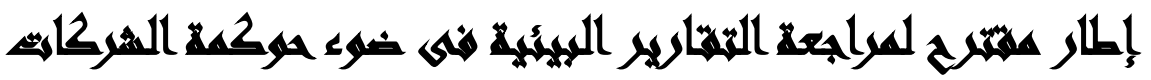 صراسمة ميدانية
}

\section{$[r \cdot]$}

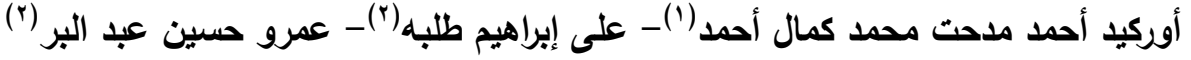

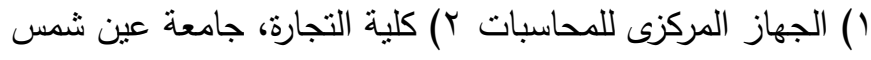

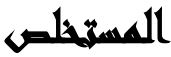

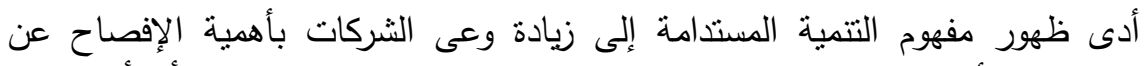

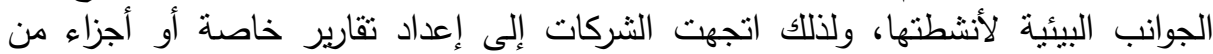

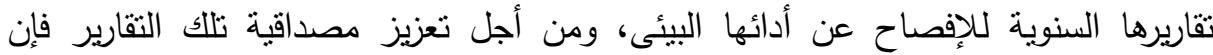

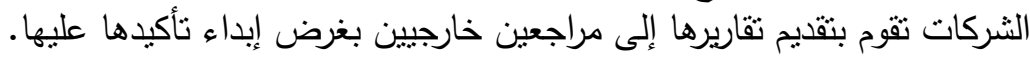

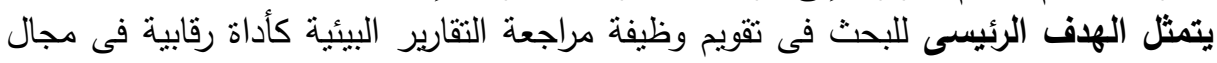
حوكمة الثركات ويتحقق هذه الهدف من خلال مجموعة من الأهداف الفرعية. يستمد هذا البحث أهمي فى الاتجاه الجديد لطرح المسائل البيئية الهامة عند الإندافئ إعداد التقارير

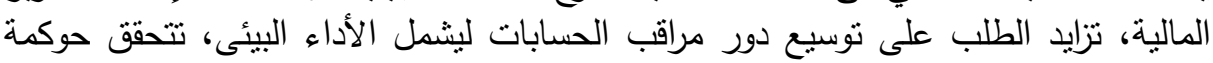

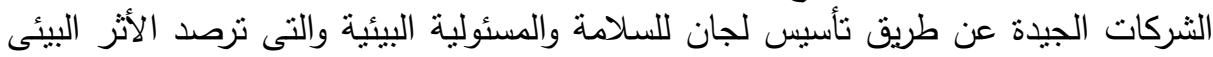

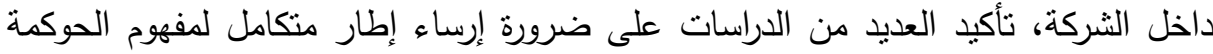
البيئية (Environmental Governance).

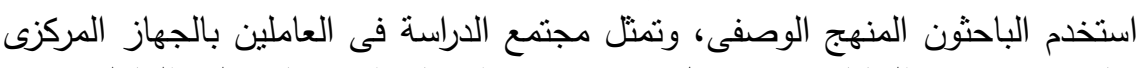

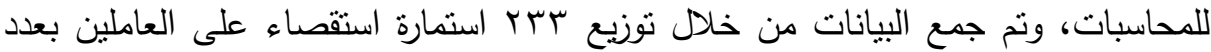

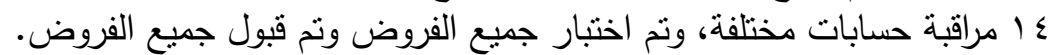

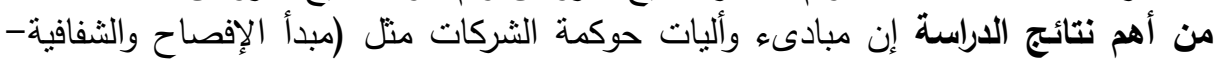

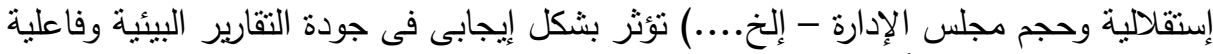

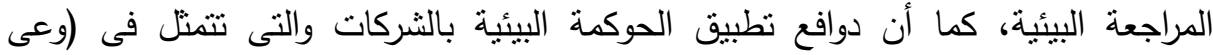
المستهلكين- ضغوط المستثرين-إلخ....) تؤثر جميعها بشكل إيجابى في الئية التقارير البيائية والمراجعة البيئية ولكن بصورة متفاوتة، وأوصت الدراستة بالأتى: فئن

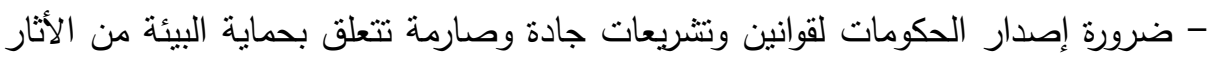
السلبية الناتجة عن أنشطة الثركات. 
- العمل على تطوير إستراتيجيات الحوكمة فى الثركات وتطويع مبادئها وألياتها لتدعم الإفصاح والتقرير البيئى.

- محاولة الأستفادة من معايير المراجعة الدولية وتطويعها بما يخدم مجال المراجعة البيئية. - كلمات مفتاحية ( المراجعة البيئية-التقارير البيئية- حوكمة الثركات- الحوكمة البيئية)

\section{Ias}

اصبح النطور السريع والمستمر فى شتى المجالات هو السمة الغالبة فى هذا العصر،

وعلى الرغم من ان هدف ودوافع هذه التطورات يأنى استجابة لتلبية احتياجات الانسان المتزايدة، فإنها قد خلفت اثارا سلبية واضحة على النواحى الاجتماعية والبيئية، منل التلوث والنفايات وارتقاع درجات الحرارة، وغيرها من الشكلات التى يجهذ العالم فى مواجهتها حاليا. أدى ذلك الى زيادة اهتمام الدول والحكومات بالمشكلات والكوارث البيئية وما نتج عنها ماتها من إيذاء للبيئة وما فيها من كائنات حية، وتمنل ذلك الاهتمام فى إنشاء جمعيات ووكالات حماية البيئة، وعمل ندوات وبرامج نطوعية للنتوعية بالأضرار البيئية، ونشر الأنظمة والقوانين بهدف الوصول إلى بيئة نظيفة تسهم فى رقى المجتمعات والمحافظة عليها(فاتح

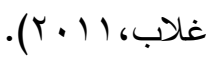

ومن ثم نشأ المفهوم الحديث للتتمية وهو ما يعرف بالتتمية المستدامة (Development)

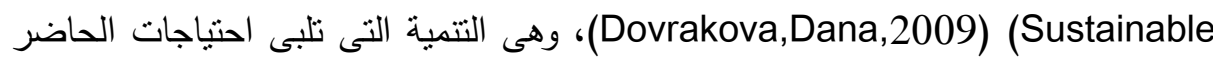
دون المساس بقدرة الأجيال المقبلة على تلبية احتياجاتها الخاصة، وتكمن الفكرة الأساسية للاستدامة فى القرارات الحالية التى ينبغى أن تحافظ على مستويات المعيثة في المستقبل

.(Mathias\&others, 2014)

لتحقيق مبادىء التتمية المستدامة، زاد وعى الثركات بأهمية الإفصاح عن الجوانب

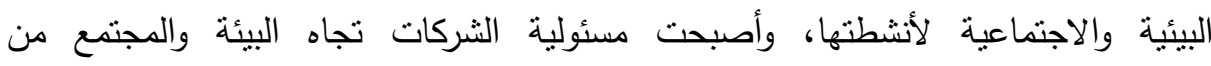
الممارسات الأساسية فى ثقافتها للحفاظ على قيمة أسهمها فى السوق، ولذية للك اتجهت المؤسسات الى اعداد تقارير خاصة أو أجزاء من تقاريرها السنوية للافصاح عن ادائها البيئى، 
وحتى تزداد الثقة فى تلك التقارير اصبحت المؤسسة تقوم بالمراجعة والتحقق من أدائها البيئى

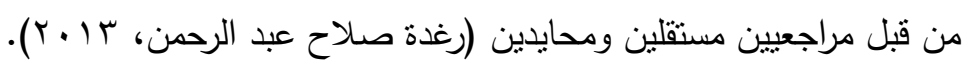

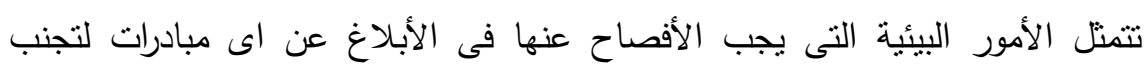

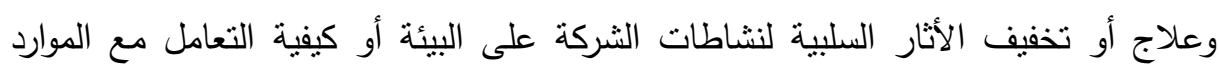
المتجددة والغير متجددة والحفاظ عليها وعواقب انتهاك القوانين والالتزامات البيئية والنتائج المترتبة على الضرر البيئى الذى حدث للأخرين أو للموارد الطبيعية.

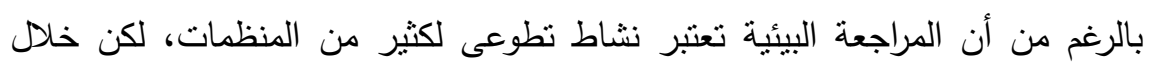
العقد الأخير أعتمد عدد من المنظمات على المراجعات البيئية بشكل كبير ، فعلى سبيل المثال

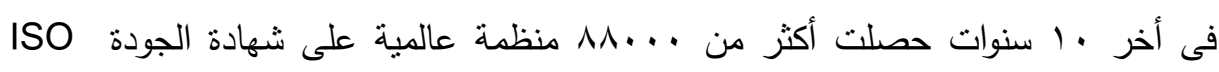

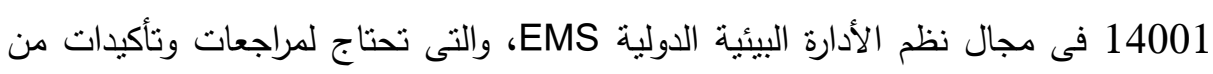

مراقبيين حسابات خارجيين للحصول عليها (Nicola,Todea\&others,2011). نجد أن التطورات الحديثة التى حصلت على وظيفة المراجعة لانتقالها من الخدمة المالية التقليدية الى مجموعة الخدمات التى تمس الجوانب البيئية، من الاليات المهمة فى تفعيل حوكمة الثركات (Corporate Governance).

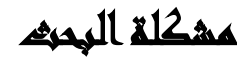

ومن خلال الدراسات السابقه التى تم عرضها بشكل تفصيلى فى الرساله ومنها دراسة (CHirstina Chiang,Deryl دراسة (Robert Dixon ,Gehan A.Mousa,2004) (Noicu ودراسة (Northcott,2010)، ودراسة)، (Nicola Todea \&others,2011)

(Idoya Ferrero\&others,2015) ودراسة)، ودراسة D,Dragomir,2012) Glass Alison Cook,2016)

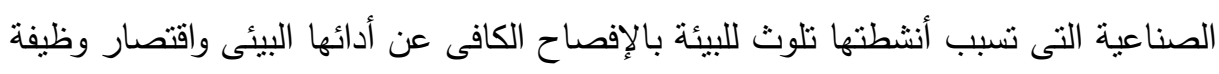

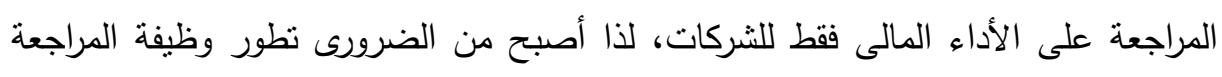

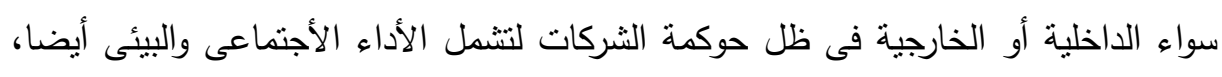
كما أصبحت الشركات تحت ضغط من الأطراف ذات المصلحة للإفصاح عن أدائها البيئى

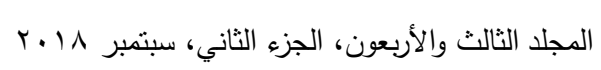


والإجتماعى بجانب أدائها المالى، ومن هنا اصبح من الضرورى ظهور وظيفة مراجعة التقارير

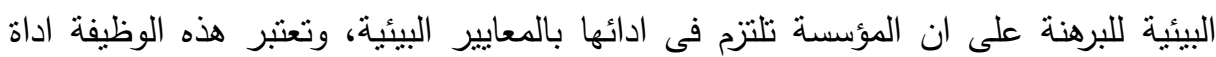
رقابية فى مجال حوكمة الثركات اى اداة لرقابة اصحاب المصلحة على ادارة المؤسسات.

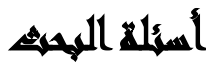

يمكن عرض مشكلة البحث من خلال الاجابة على السؤال الرئيسى التالى الذى يمثل جوهر المشكلة وهو " ما الاطار العام لمراجعة التقارير البيئية فى ضوء حوكمة الثركات"؟ ويستمد من هذا السؤال عدة اسئلة منها:

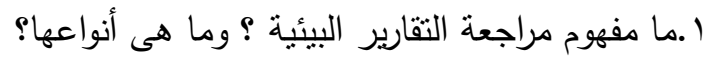

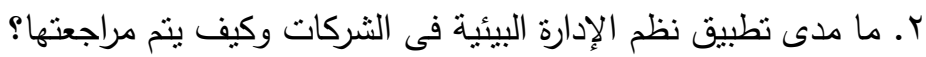

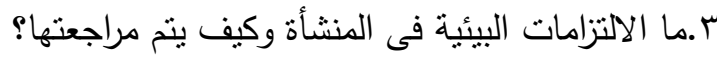
ع .ما دور مراقب الحسابات فى مراجعة التقارير البيئية ؟ ه.ما أمكانية قيام المراجعون الداخليون بمراجعة الاداء البيئى اضافة الى الاداء المالى فى لى لئي

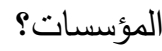

7.ما أهمية الأفصاح عن المسائل البيئية للشركات ودورها فى تفعيل الحوكمة؟ V. ما الاثار الحوكمية لمراجعة التقارير البيئية والتحقق من جوانب التتمية المستدامة فى

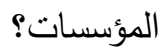
1.ما أمكانية تطبيق اليات الحوكمة لتفعيل دور المراجعة البيئية؟

\section{أهمية المهمه}

- يستمد هذا البحث اهميتة من تزايد الاهتمام بموضوع التتمية المستدامة فى السنوات الاخيرة،

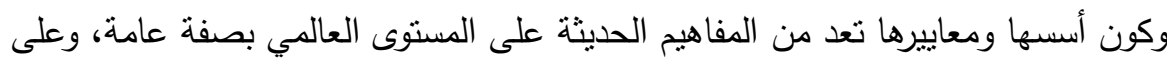
المستوى المحلي بصفة خاصة. - الأتجاة الجديد لطرح المسائل البيئية الهامة عند إعداد التقارير المالية والذى بدوره أدى الى لى توسيع نطاق مهنة المراجعة المالية لتغطية القضايا البيئية. 
- إعتراف مهنة المراجعة بأهمية الأفصاح عن المسائل البيئية فى عدد كبير من الكيانات الأقتصادية وقد تكون فى بعض الظروف ذات أثز مادى على التقارير المالية لهذه الكيانات بل أصبحت هذه القضايا ذات أهتمام منزايد لدى مستخدمى التقارير المالية.

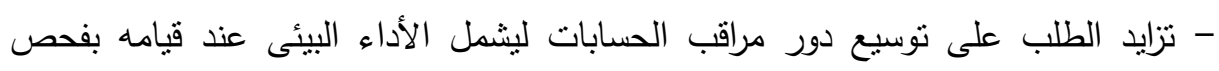
التقارير المالية للشركات.

- تتحقق حوكمة الثركات الجيدة عن طريق تأسيس لجان للسلامة أو المسئولية البيئية والتى

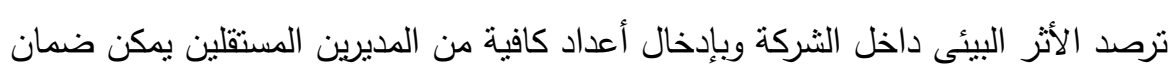

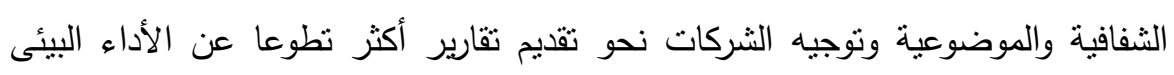

والجوانب الأخرى.(Lenciu,Lonel-Alin\&others,2012).

- تعدد المشكلات المرتبطة بمفهوم المراجعة البيئية فهو مفهوم غير معرف بوضوح عالميا ولا يتصل بمجموعة محدده من النشاطات.

- تأكيد العديد من الدراسات على ضرورة ارساء اطار متكامل لففهوم الحوكمة البيئية والذى يثير الى مجموعة الانظمة والقواعد التى (Environmental Governance) تقوم بارساء الضوابط اللازمة للحفاظ على مكونات البيئة والتتمية المستدامة.

\section{أهسا اهن المهمث}

يتمثل الهدف الرئيسى للبحث فى: " تقويم وظيفة مراجعة التقارير البيئية كاداة رقابية فى

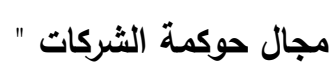
ويتحقى ذلك من خلال مجموعة من الاهداف الفرعية منها: ( ) للتعرف على ماهية المراجعة البيئية وأنواعها

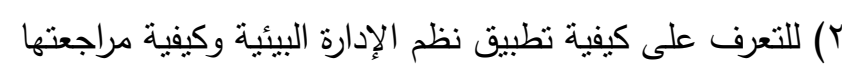

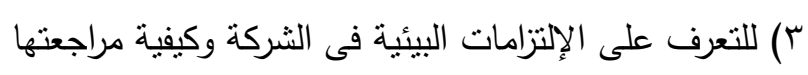
ع) للتعرف على دور مراقب الحسابات فى المراجعة البيئية

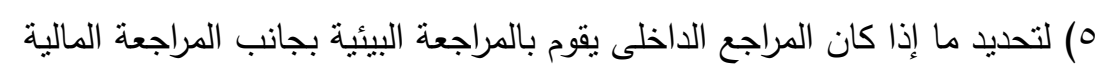

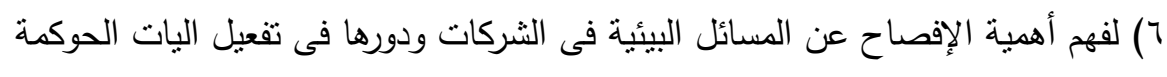

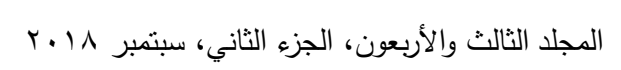


مجلة العلوم البيئية

معهد الدراسات والبحوث البيئية - جامعة عين شمس

V للتعرف على الأثار الحوكمية للمراجعة البيئية ^) لتحديد كيفية تطبيق اليات حوكمة الثركات لتفعيل دور المراجعة البيئية

\section{هروض المهنه}

H01 لا يوجد علاقة إحصائية ذات دلالة جوهرية بين مبادىء وأليات حوكمة الثركات وجودة التقارير البيئية.

HA1 يوجد علاقة جوهرية ذات دلالة إحصائية بين مبادىو أليات حوكمة الثركات وجودة

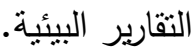

H02 لا يوجد علاقة إحصائية ذات دلالة جوهرية بين أليات حوكمة الشركات وفاعلية

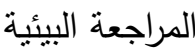
HA2 يوجد علاقة إحصائية ذات دلالة جوهرية بين أليات حوكمة الثركات وفاعلية المراجعة البيئية.

H:H03 يوجد علاقة إحصائية ذات دلالة جوهرية بين التقارير البيئية ودوافع نطبيق الحوكمة

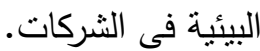
HA3 يوجد علاقة إحصائية ذات دلالة جوهرية بين التقارير البيئية ودوافع تطبيق الحوكمة البيئية فى الثركات. H04 لا يوجد علاقة إحصائية ذات دلالة جوهرية بين المراجعة البيئية ودوافع نطبيق الحوكمة البيئية فى الثركات.

HA4 يوجد علاقة إحصائية ذات دلالة جوهرية بين المراجعة البيئية وتطبيق الحوكمة البيئية

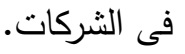

\section{السواسايت المربعية}

تعرضت دراسة (Robert Dixon,Gehan A.Mousa,2004): إلى الخصائص الضرورية للمراجعين البيئيين، وتهدف هذه الدراسة إلى التعرف على دور مهنة المراجعة المالية فى مجال المراجعة البيئية، والتعرف أيضا على قدرة المراجع المالى فى تقييم الأثار 502

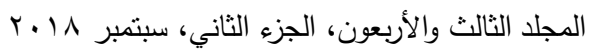


البيئية للأعمال التجارية والمشاركة فى المراجعة البيئية،و توصلت هذه الدراسة إلى أنه يمكن

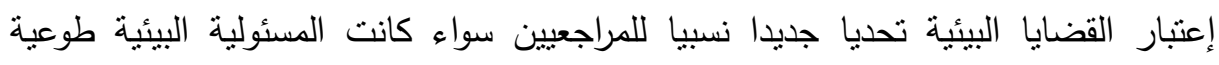

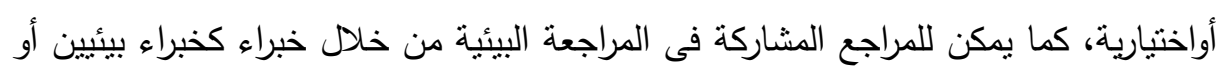
مهندسين أو محاميين ومازال دور المراجع محدود فى المراجعة البيئية. تطرقت دراسة:(CHirstina Chiang, Deryl Northcott,2010) إلى اهنمام المراجعة بالمسائل البيئية، وهدفت الدراسة لإختبار استجابات المراجعين النيوزلانديين لمعايير المراجعة الإرشادية (•1.1) والتى تهتم بمراجعة المسائل البيئية ضمن القوائم المالية،

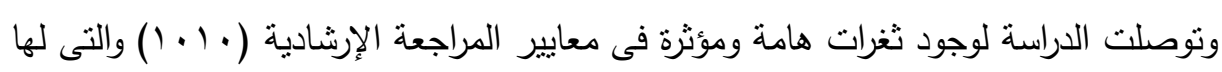

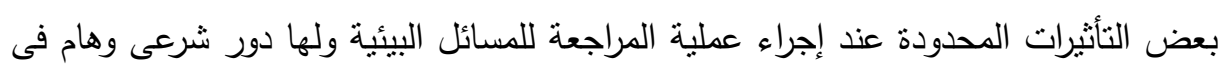
دعم جهود المراجعين والاستجابة إلى المسائلة. تعرضت دراسة (NicolaeTodea\&others,2011) للمراجعة البيئية كمصدر

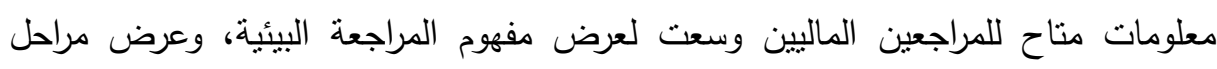

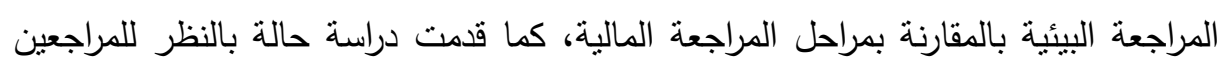

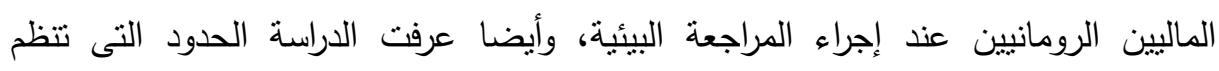

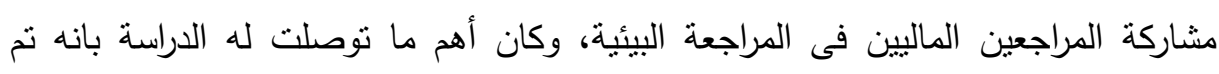

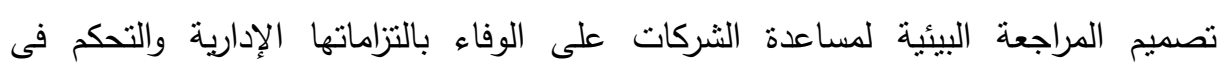

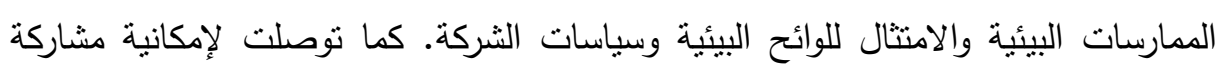
المراجع فى المراجعة البيئية من خلال خبراء كخبراء بيئين او مهندسين الوانئ أو محامين.

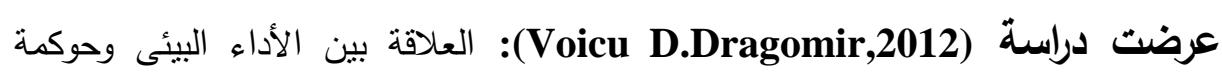

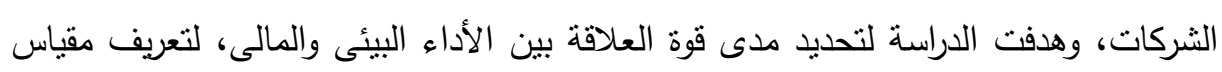

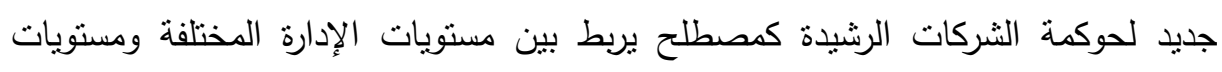

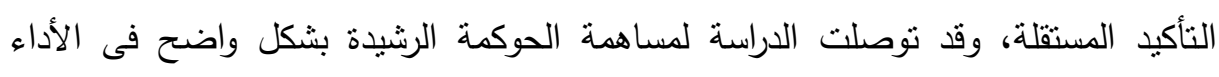

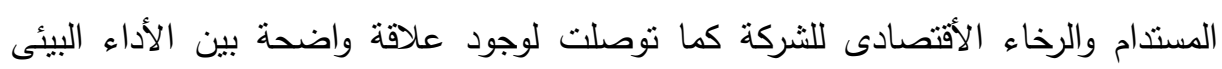
والاقتصادى.

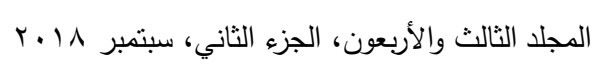


قدمت دراسة (Idoya Ferrero \& others,2015) كيفية تكامل الاستدامة مع حوكمة الثركات من خلال دراسة تجريبية حول تتوع مجلس الإدارة بالثركة وسعت الدراسة لتوضيح مدى تأثير التتوع فى مجلس الإدارة على جودة إدارة المسئولية الإجتماعية والبيئية للشركات

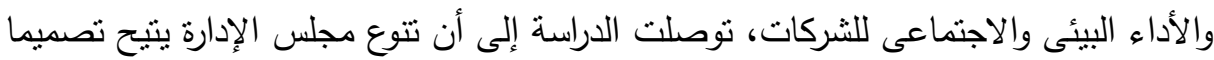

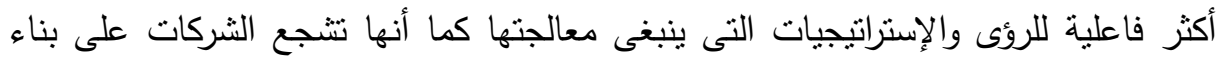

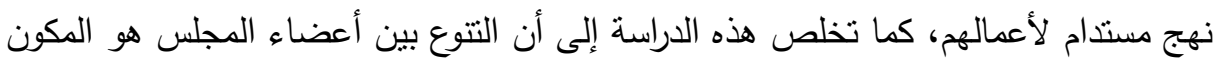
الأساسى لتحسين قواعد حوكمة الثر كات الجيدة. وضحت دراسة (Christy Glass Alison Cook,2016 ) تأثثر المدراء النساء على الأستراتيجيات البيئية للشركات، وتوصلت الدراسة إلى أن الثركات النى يديرها النساء ويكون

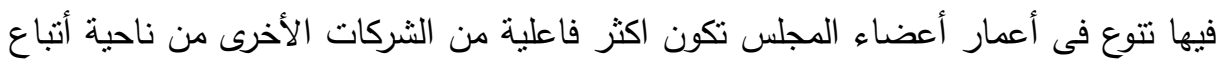
الأستراتيجيات الصديقة للبيئة. ومعظم الدراسات السابقة لم تنطرق لتأثير أليات ومبادىء حوكمة الثركات على مدى لهى فاعلية المراجعة البيئية وجودة التقارير البيئية ولم تضع إطار واضح للمعايير المقترحة للمراجعة البيئية ويعتبر هذا دافع لإجراء الدراسة.

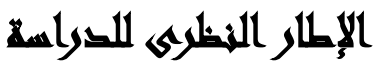

شهدت وظيفة المراجعة تطوراً كبيراً خلال العقدين الماضيين وأصبحت ثقوم بمراجعة كافة أنشطة المنشأة الاقتصادية، مما تتطلب ضرورة إعادة تأهيل المراجع علميا وعمليا حتى كئى يستطيع القيام بالوظائف الجديدة للمراجعة وتطبيق الإصدارات المهنية المختلفة التى تصدرها

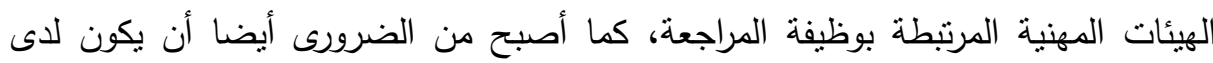

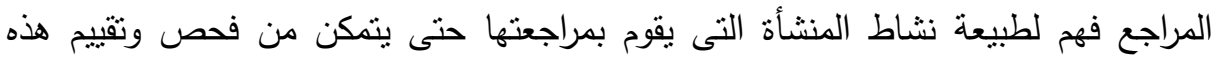

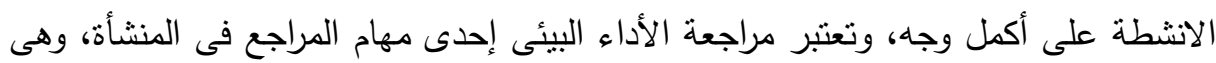

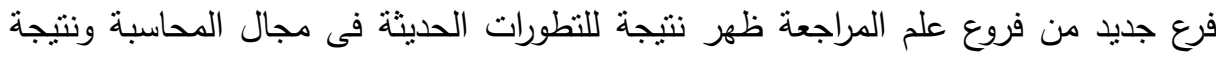
أيضا لالتزام الوحدات الأقتصادية نحو القضايا والقوانين البيئية وأثز ذلك على النظم المحاسبية 
بتلك الوحدات، كما ان المراجعة البيئية تعمل كأداة رقابة هامة وجزأ لا يتجزأ من هيكل حوكمة

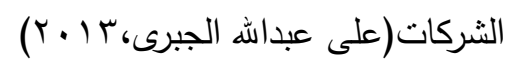
ويركز الباحث فى دراسته للإطار النظرى للمراجعة البيئية على النقاط التالية:

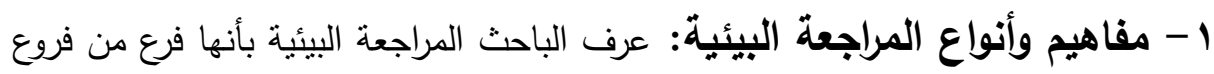
المراجعة تقوم على إجراء فحص دورى ومنظم لكافة التقارير التى تصدرها المنشأة بشأن مسئولياتها تجاه البيئة، كما أنها تهدف لتقبيم موثق لمدى كفاءة نظام الإدارة البيئية ومدى دورى

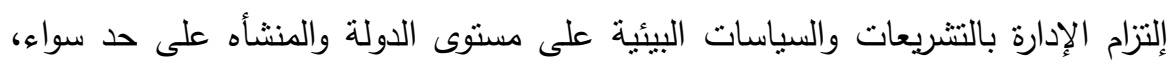
وتتم عملية المراجعة البيئية إما من طرف المنشأة بالأعتماد على قسم المراجعة الداخلية

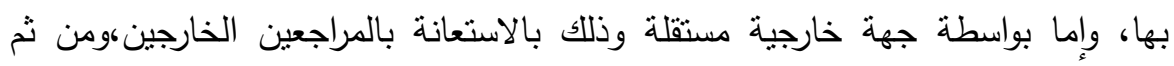

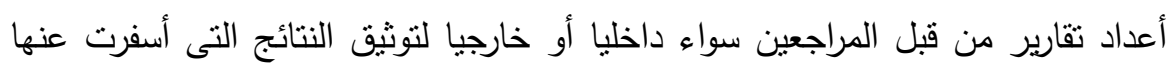

$$
\text { عملية المراجعة وتوصيلها للأطراف المهتمة. }
$$
المراجعة البيئية يمكن تصنيفها كالأتى:

• مراجعة الألتزام التنظيمى: تعتبر مراجعة الالتزام التتظيمى من أكثر أنواع المراجعة البيئية

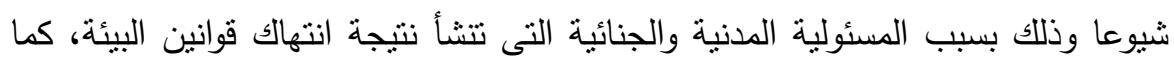
تتضمن مراجعة الالتزام ثلاثة أنشطة هامة :

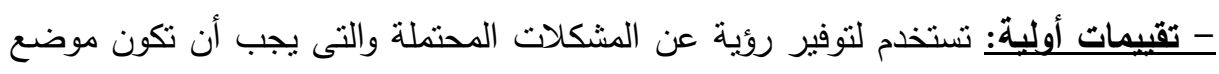
اهتمام أنشطة المراجعة فى المستقبل. - المراجعة البيئية: هى مراجعة تفصيلية للعمليات والأنشطة ذات النأثير البيئى كما أنها تقيس مدى الألتزام بالحدود والنسب المسموح بها. - فحص بيئى وتقييم مواقع: هى مراجعة تفصيلية يتم القيام بها اذا ما أظهرت المرحلة السابقة اى انتهاكات بيئية . • مراجعة نظم الإدارة البيئية: هى عملية المراجعة التى صممت خصيصا للتحقق وتقييم

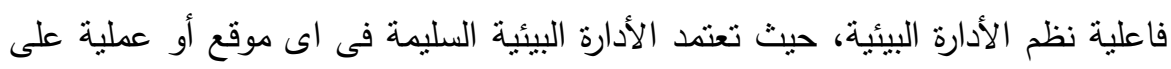

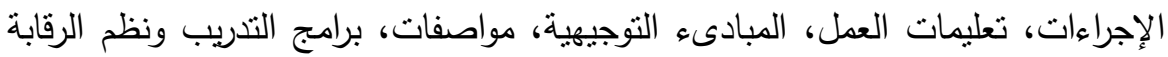

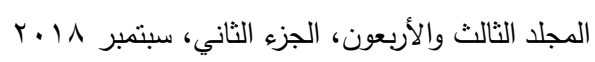


التى ينم تتفيذها من قبل موظفى المنظمة القائمة على الموقع( Department of Environmental Affairs and Tourism,2004) • مراجعة المعالجة والتخلص من النفايات بمجرد وضع برنامج للتقليل من النفايات للحد

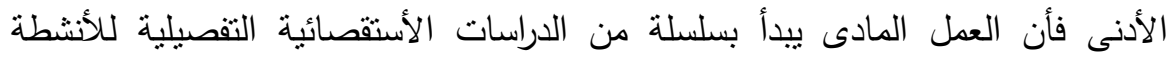

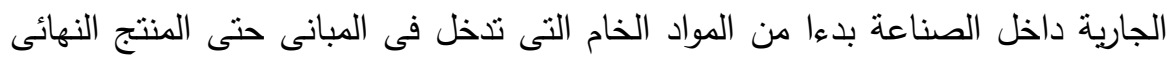

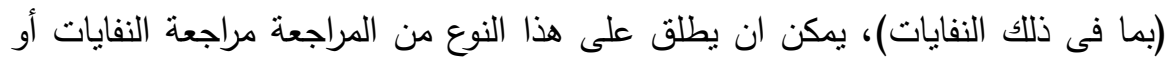
مراجعة تقليل النفايات(Kutz c05.tex,2011). r - المعايير المقترحة لمراجعة التقاريز البيئية: أكدت دراسة معهد المحاسبين القانونين بأنجلترا وويلز على أهمية أن يكون مراقب الحسابات على دراية نامة بإطار المعايير المهنية والقانونية الذى يقوم من خلاله بمراجعة تأثير العوامل البيئية على القوائم

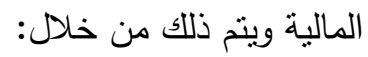

الإلمام بالمعايير الصادرة عن الهيئات المهنية التالية: - معايير وإرشادات المراجعة الدولية الصادرة عن لجنة ممارسات المراجعة الدولية (IAPC) التابعة للأتحاد الدولى للمحاسبين ( IFAC). - معايير المحاسبة الدولية الصادرة عن لجنة معايير المحاسبة الدولية (IASC). - إصدارات المعهد الأمريكى للمحاسبين القانونين (AICPA) - معايير المراجعة والمحاسبة الخاصة بالمنطقة أو الدولة التى تعمل بها مكاثب المحاسبة والمراجعة المعنية. - الإلمام بقانون الثركات الخاص بالدولة محل المراجعة كما يجب أن يذكر مراقب الحسابات

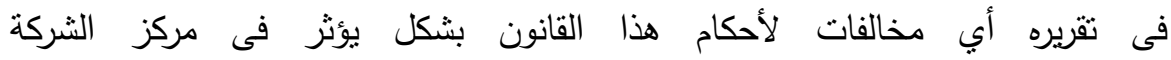

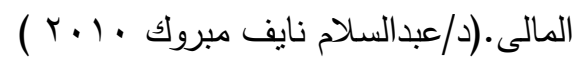
r- تأثير سمات وآليات حوكمة الثركات على افاعلية المراجعة البيئية: أن مبدأ أساسى من مبادىء حوكمة الثركات هو الأفصاح والثفافية عن جميع المسائل الخاصة بالثركة بما فيها المسائل البيئية ومن ناحية أخرى فإن أليات حوكمة الثركات (حجم 
المجلس - ملكية الأسهم فى الثركات- استقلالية المدراء وإزدواجية المدير التتفيذى لجان المراجعة) تؤثر بشكل واضح فى جودة الإفصاحات والتقارير البيئية. ومن ثم فاعلية المراجعة البيئية.

\section{إلبراعاهت الدواسمة}

حدود البحث:

- من الناحية الميدانية أقتصر نطاق مجتمع البحث على بعض مراقبات الحسابات بالجهاز

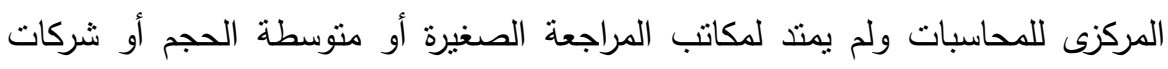

$$
\text { المراجعة الكبيرة. }
$$

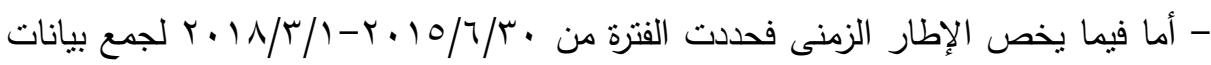
البحث.

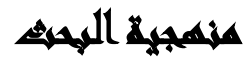

\section{يعتمد الباحث على الجمع بين الاراسة النظرية والدراسة الميدانية:}

- الدراسة النظرية: تهدف الدراسة لصباغة الإطار النظرى والوصول إلى الفجوة البحثية

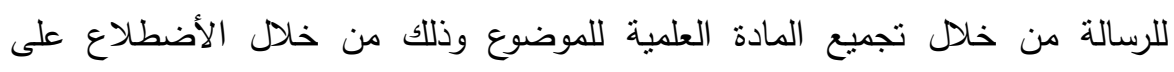

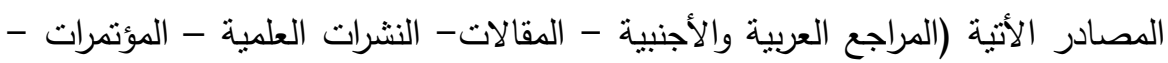
الكتب....ألخ)

- الدراسة الميدانية: استخدم الباحث المنهج الوصفى ونم تجميع البيانات من مصادرها الأولية من خلال استمارة الأستقصاء والتى تم توزيعها على عينة من العاملين بإدارات ومراقبات الجهاز المركزى للمحاسبات لما لديهم من خبرات في هذا المجال.

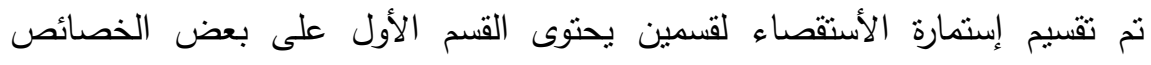
والسمات الثخصية لأفراد عينة الدراسة، ويحتوى القسم الثانى على الإستفسارات الخاصة الثناه

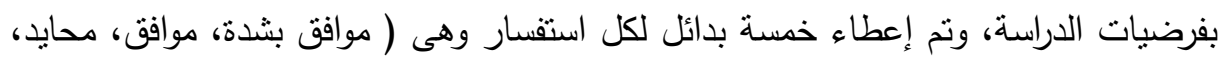


غير موافق، غير موافق بشدة)، وقد تم تفريغ البيانات وتحليل النتائج باستخدام البرنامج الإحصائى SPSS.

تمثل حجم عينة الدراسة بحوالى برم استمارة تم توزيعهم على مراقبات الحسابات

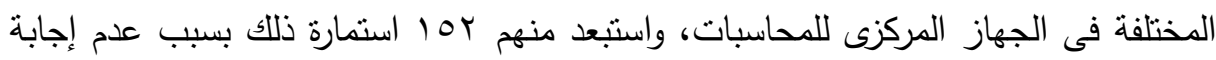

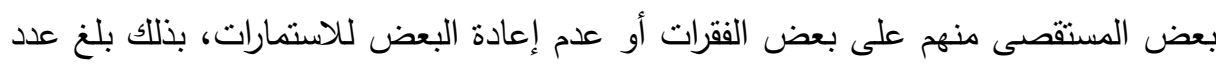

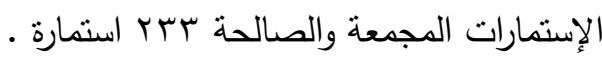

وقد تم إستخلام عدة أساليب إحصائية من أجل توظيف البيانات التى تم جمعها لتحقيق أغراض الدراسة ويتضح ذلك فى الأتى:

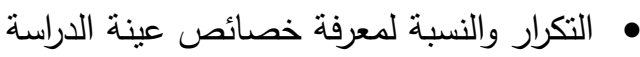
• • • • • • • • معامل الإرنباط البسيط لقياس Simple correlation coefficient قوة واتجاه العلاقة بين متغيرات البحث

Simple إسلوب الانحدار البسيط المتغير المستقل على المتغير التابع. لتحديد مدى تأثنيرات

Regreesion • اختبار ألفاكرونباخ Cronbach's alpha) لقياس مدى صدق وثبات قائمة الاستقصاء.

\section{Reliability Statistics}

\section{Cronbach's Alpha .879}

\section{$\mathrm{N}$ of Items} 30

المصدر : مخرجات برنامجSPSS

بلغ معامل النبات ألفا لأفراد العينة كوحدة واحدة وقائمة الأستقصاء بشكل عام

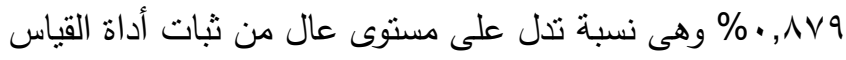




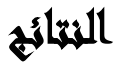

الفرض الأول: لا يوجد علاقة إحصائية بين جودة التقارير البيئية ومبادىء وآليات حوكمة الشركات

للتحقق من صحة الفرض تم إستخدام معامل الإرتباط المتعدد والانحدار المتعدد بطريقة

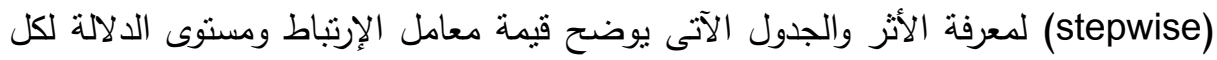
قيمة معامل الإرتباط ومستوى الدلالة لمعرفة العلاقة بين جودة التقارير البيئية مبادى وآليات حوكمة الثركات

\begin{tabular}{|c|c|c|}
\hline مستوى الدلالة & معامل الإرتباط & المتغير المستقل \\
\hline$\cdot, \cdots$ & $\cdot, r \wedge 9$ & مبداً الإفصاح والثفافية \\
\hline$\cdot, \cdots$ & $\cdot, 7 \wedge 1$ & حجم مجلس الإدارة \\
\hline$\cdot, \cdots$ & $\cdot, \leqslant \vee \wedge$ & إستقلالية مجلس إدارة الَشركة \\
\hline$\cdot, \cdots$ & $\cdot, 0 \cdot \mathrm{V}$ & ملكية أعضاء المجلس في أسهم الشركة \\
\hline$\cdot, \cdots$ &., 099 & لجان المراجعة \\
\hline
\end{tabular}

مما سبق ينضح وجود علاقة إحصائية ذات دلالة جوهرية بين جودة التقارير البيئية ومبادىء وأليات حوكمة الثركات. من خلال ذلك يمكن للباحث معرفة مقدار التأثير لمبادىء وآليات حوكمة الثركات على ئى جودة التقارير البيئية بإجراء تحليل الانحدار المتعدد. المتغير التابع : جودة التقارير البيئية المتغير المستقل : مبادىء وآليات حوكمة الثركات 
نتائج تحليل التباين (ANOVA)

\begin{tabular}{|c|c|c|}
\hline نموذج الاتحدار & $\bar{F}$ & Sig \\
\hline 1- حجم مجلس الإدارة & 200.209 & 0.00 \\
\hline ץ- حجم مجلس الإدارة، إستقلالية مجلس الإدارة & 188.062 & 0.00 \\
\hline المراجعة حجل الإدارة، إستقلالية مجلس الإدارة، لجان & 197.354 & 0.00 \\
\hline 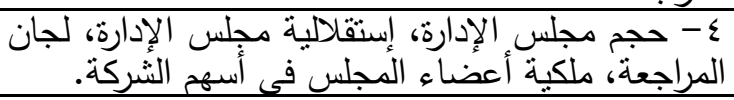 & 235.255 & 0.00 \\
\hline 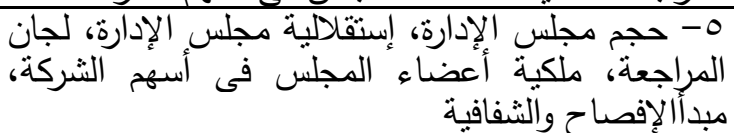 & 272.251 & 0.00 \\
\hline
\end{tabular}

يوضح الجدول نتائج تحليل التباين ANOVA لإختبار معنوية الانحدار ونلاحظ عند

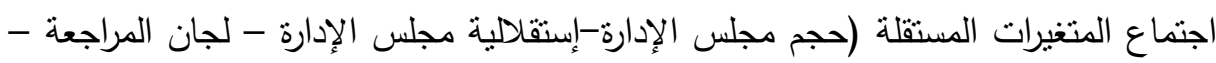

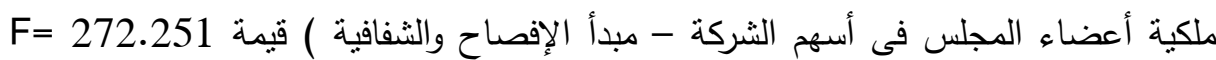

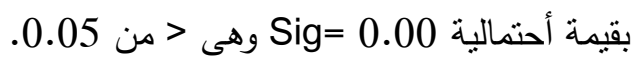

وبالتالى نرفض فرض العدم ونقبل الفرض البديل يوجد علاقة إحصائية ذات دلالة جوهرية بين جودة التقارير البيئية ومبادىه واليات حوكمة الثركات. لتحديد معادلة الانحدار - معاملات نموذج الانحدار

\begin{tabular}{|c|c|c|c|}
\hline \multirow{2}{*}{ Sig } & $T$ & $\bar{\beta}$ & المتغير المستقل \\
\hline & $r, 919$ & 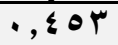 & الثابت \\
\hline 0.00 & $17,1 \wedge Y$ & $\cdot, Y \cdot O$ & حجم مجلس الإدارة \\
\hline 0.00 & 11,079 & $\cdot, 1 \vee 0$ & إستقلالية مجلس الإدارة \\
\hline 0.00 & $\Lambda, 9 \vee 9$ & $\cdot, 100$ & لجان المراجعة \\
\hline 0.00 & צ & $\cdot, 177$ & ملكية أعضاء المجلس فى أسهح \\
\hline 0.00 & $9, \cdot 9 r$ & $\cdot, 1 \wedge \varepsilon$ & مبداً الإفصاح والثفافية \\
\hline
\end{tabular}

وتصبح معادلة الانحدار

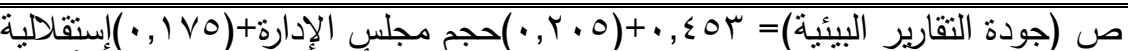

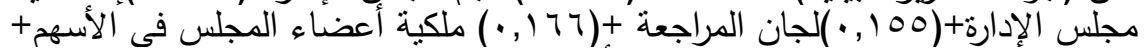

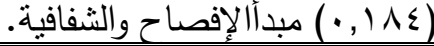




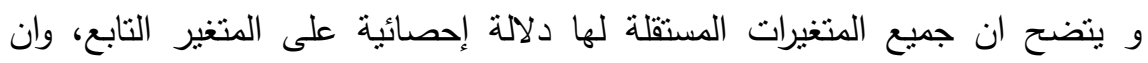

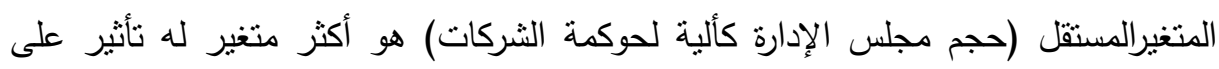
المتغير التابع (جودةالتقارير البيئية ) بمقدار (0. ب, •).

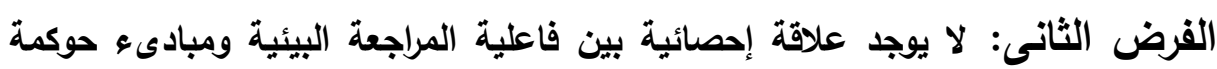
الثركات

للتحقق من صحة الفرض نت إستخدام معامل الإرتباط التنعدد والانحدار المتعدد بطريقة

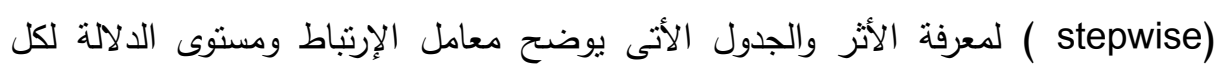

قيمة معامل الإرتباط ومستوى الدلالة لمعرفة العلاقة بين فاعلية المراجعة البيئية متغير: وحوكمة الثركات

\begin{tabular}{|c|c|c|}
\hline مستوى الدلالة & معامل الإرتباط & المتغير المستقل \\
\hline$\Rightarrow, \ldots$ & . & لجان المراجعة \\
\hline$\cdot, \cdots$ & $\cdot, V \leqslant \varepsilon$ & كفاءة الإدارة التتفيذية \\
\hline$\cdot, \cdots$ & $\cdot, V \backslash \Gamma$ & المراجعة الداخلية \\
\hline
\end{tabular}

مما سبق يتضح وجود علاقة إحصائية ذات دلالة جوهرية بين فاعلية المراجعة البيئية

$$
\text { ومبادىء حوكمة الشركات. }
$$

من خلال ذلك يمكن للباحث معرفة مقدار التأثير لمبادىء حوكمة الثركات على فاعلية

المراجعة البيئية بإجراء تحليل الانحدار المتعدد بطريقة (stepwise) المتغير التابع : فاعلية المراجعة البيئية المتغير المستقل : مبادىء حوكمة الثركات

ANOVA نتائج تحليل الاتحدار

\begin{tabular}{|c|c|c|}
\hline نموذج الانعدار & $\mathbf{F}$ & Sig \\
\hline - - كفاءة الإدارة التنفيذية & 286.619 & $\overline{0.00}$ \\
\hline r- كفاءة الإدارة التنفيذية، المراجعة الداخلية & 265.581 & 0.00 \\
\hline ץ- حجم مجلس الإدارة، إستقلالية مجلس الإدارة، لجان المراجعة & 253.109 & 0.00 \\
\hline
\end{tabular}


يوضح الجدول نتائج تحليل التباين ANOVA لإختبار معنوية الانحدار ونلاحظ عند

أجتماع المتغيرات المستقلة (كفاءة الإدارة التتفيذية-المراجعة الداخلية- لجان المراجعة) قيمة لإندانة

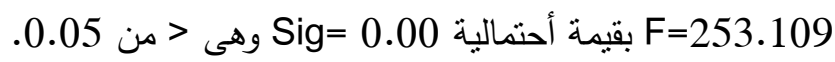

و بالتالى نرفض فرض العدم ونقبل الفرض البديل يوجد علاقة إحصائية ذات دلالة جوهرية بين فاعلية المراجعة البيئية وأليات حوكمة الشركات. لتحديد معادلة الانحدار

معاملات نموذج الانحدار

\begin{tabular}{|c|c|c|c|}
\hline \multirow{2}{*}{ Sig } & $T$ & $\bar{\beta}$ & المتغير المستقل \\
\hline & $0, \vee r \wedge$ & $\cdot, \vee \vee \wedge$ & الثابت \\
\hline 0.00 & $\Lambda, r \leqslant 0$ & $\cdot, Y V$. & لجان المراجعة \\
\hline 0.00 & $11, \varepsilon \cdot 7$ & $\cdot \pi$ & كفاءة الإدارة التتفيذية \\
\hline 0.00 & $9, \cdot V \cdot$ & $\cdot$, YTA & المراجعة الداخلية \\
\hline
\end{tabular}

وتصبح معادلة الانحدار =

ص (فاعلية المراجعة البيئية)=

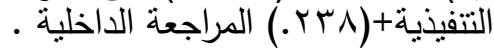

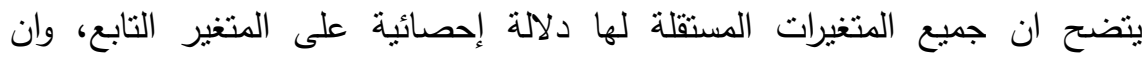

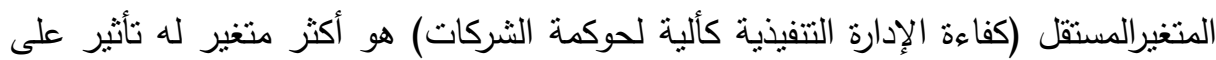

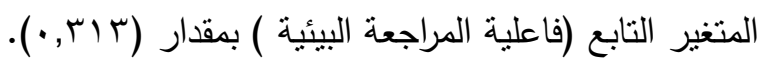

الفرض الثالث: لا يوجد علاقة جوهرية بين التقارير البيئية ودوافع تطبيق الحوكمة البيئية

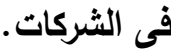

للتحقق من صحة الفرض تم إستخدام معامل الإرتباط المتعدد والانحدار المتعدد بطريقة

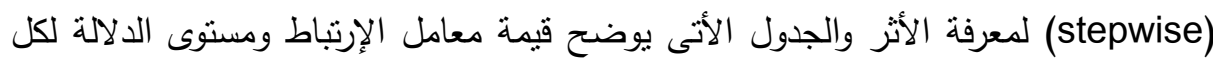
متغير : n 
قيمة معامل الإرتباط ومستوى الدلالة لمعرفة العلاقة بين المراجعة البيئية ودوافع الاهتمام بالحوكمة البيئية في الثركات

\begin{tabular}{|c|c|c|}
\hline مستوى الدلالة & معامل الإرتباط & المتغير المستقل \\
\hline$\cdot, \cdots$ & $\cdot, r \vee q$ & الوعى البيائى لدى المستهلكين. \\
\hline$\cdot, \ldots$ & $\cdot, Y Y M$ & ضغوط المساهمين والمستثمرين \\
\hline$\cdot, \ldots$ & $\cdot$, YAY & إحتياج البنوك لمعلومات بيئية \\
\hline$\cdot, \ldots$ & $\cdot, 401$ & القوانين والسياسات البيئية. \\
\hline$\cdot, \ldots r$ & $\cdot, 1 \wedge \varepsilon$ & ضغوط الجماعات البيئية \\
\hline
\end{tabular}

مما سبق يتضح وجود علاقة إحصائية ذات دلالة جوهرية بين المراجعة البيئية ودوافع

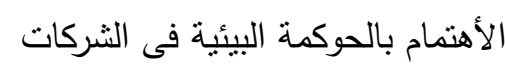
من خلال ذلك يمكن للباحث معرفة مقدار التأثير لدوافع الأهتمام بالحوكمة البيئية فى بـ الثركات على المراجعة البيئية بإجراء تحليل الانحدار المتعدد. المتغير التابع : المراجعة البيئية المتغير المستقل: دوافع الأهتمام بالحوكمة البيئية فى الثركات التئه

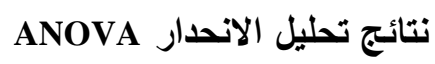

\begin{tabular}{|c|c|c|}
\hline نموذج الانحـار & $\mathbf{F}$ & Sig \\
\hline 1 الوعى البيئي للمستهلكين & $\overline{38.861}$ & 0.00 \\
\hline ץ- الوعى البيئي للمستهلكين، السياسات والقوانين البيئية & 30.675 & 0.00 \\
\hline
\end{tabular}
يوضح الجدول نتائج تحليل التباين ANOVA لإختبار معنوية الانحدار ونلاحظ عند اجتماع المتغيرات المستقلة (الوعى البيئى للمستهلكين-السياسات والقوانين البيئية ) قيمة

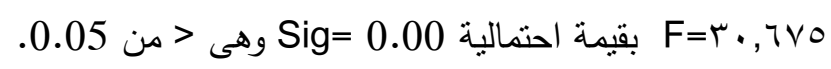
وبالتالى نرفض فرض العدم ونقبل الفرض البديل يوجد علاقة إحصائية ذات دلالة جوهرية بين المراجعة البيئية ودوافع تطبيق الحوكمة البيئية فى الثركات. لتحديد معادلة الانحدار ومعرفة أكثر متغير له دلالة إحصائية. 
معاملات نموذج الانحدار

\begin{tabular}{|c|c|c|c|}
\hline \multirow{2}{*}{ Sig } & $\mathbf{T}$ & $\beta$ & المتغير المستقل \\
\hline & $1,, Y 07$ & $r, r, \theta$ & الثابت \\
\hline 0.00 & $0, .0 r$ & $\cdot, 191$ & الوعى البيئي للمستهكين \\
\hline 0.00 & $\varepsilon, \varepsilon \cdot \varepsilon$ & $\cdot, Y \backslash 1$ & القوانين والسياسات البيئية \\
\hline 0.394 & -- & -- & ضغوط المستتمرين والمساهمين \\
\hline 0.085 & -- & -- & حاجة البنوك لمعلومات بيائية \\
\hline 0.088 & -- & -- & ضنوط الجماعات البيئية \\
\hline
\end{tabular}

وتصبح معادلة الانحدار =

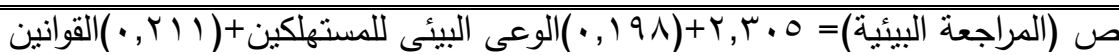
والسياسات البيئية.

و يتضح ان المتغيرات المسنقلة التى لها أكثر دلالة إحصائية على المتغير التابع هى

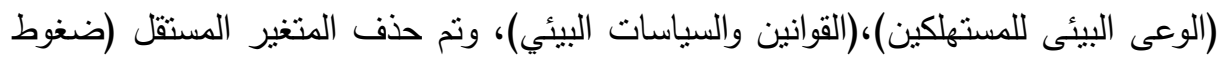

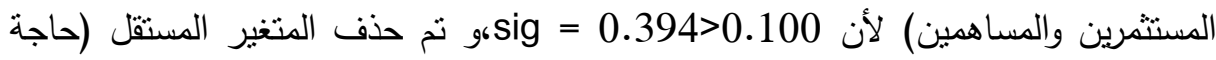

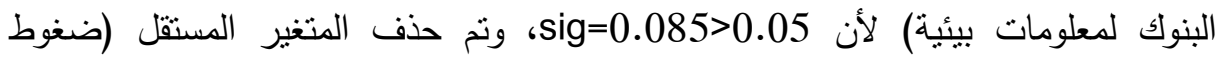
الجماعات البيئية) لأن ل0.

الفرض الرابع: لا يوجد علاقة جوهرية بين التقارير البيئية ودوافع تطبيق الحوكمة البيئية

\begin{tabular}{|c|c|c|}
\hline مستوى الدلالة & معامل الإرتباط & المتغير المستقل \\
\hline$\cdot, \cdots$ & $\cdot, \Sigma Y V$ & الوعى البيأي لدى المستهلكين. \\
\hline$\cdot, \cdots$ & $\cdot \pi \| \mu$ & ضغوط المساهمين والمستثمرين \\
\hline$\cdot, \ldots$ & $\cdot, Y 7 \mu$ & إحتياج البنوك لمعلومات بيئية \\
\hline$\cdot, \ldots$ & $\cdot, \Gamma \leq \mu$ & القوانين والسياسات البيئية. \\
\hline$\cdot, \cdots 1$ & $\cdot, Y \backslash \leqslant$ & ضغوط الجماعات البيئية \\
\hline
\end{tabular}

للتحقق من صحة الفرض نم استخدام معامل الإرتباط المتعدد والانحدار المتعدد بطريقة

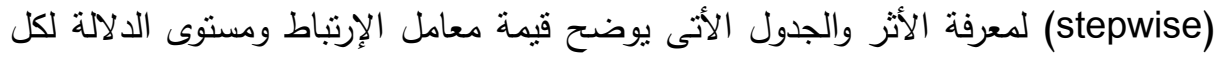
قيمة معامل الإرتباط ومستوى الدلالة لمعرفة العلاقة بين التقارير البيئية ودوافع الأهتمام

$$
\text { بالحوكمة البيئية فى الشركات معلم الإنباط }
$$


مما سبق يتضح وجود علاقة إحصائية ذات دلالة جوهرية بين الثقارير البيئية ودوافع الأهتمام بالحوكمة البيئية فى الثركات وجنيق

من خلال ذلك يمكن للباحث معرفة مقدار التأثثر دوافع الأهتمام بالحوكمة البيئية فى لئي الشركات على التقارير البيئية بإجراء تحليل الانحدار المتعدد. المتغير التابع : التقارير البيئية المتفير المستقل : دوافع الأهتمام بالحوكمة البيئية فى الثركات

\begin{tabular}{|c|c|c|}
\hline نموذج الانعدار & $\mathbf{F}$ & Sig \\
\hline 1 - الوعى البيئي للمستهلكين & 51.581 & 0.00 \\
\hline ץ- الوعى البيئي للمستهلكين،السباسات والقوانين البيائية & 36.040 & 0.00 \\
\hline 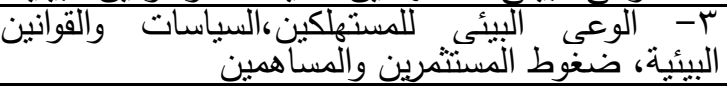 & 26.489 & 0.00 \\
\hline 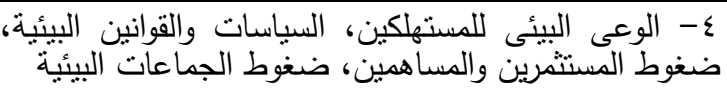 & 21.092 & 0.00 \\
\hline
\end{tabular}

(ANOVA) تتائج تحليل التباين

يوضح الجدول نتائج تحليل التباين ANOVA لإختبار معنوية الانحدار ونلاحظ عند

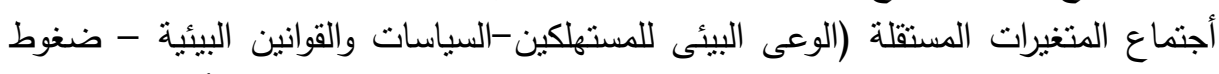
Sig= بقيمة أحتمالية

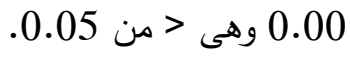

وبالتالى نرفض فرض العدم ونقبل الفرض الفرض البديل يوجد علاقة إحصائية ذات دلالة جوهرية بين التقارير البيئية ودوافع نطبيق الحوكمة البيئية فى الثركات. لتحديد معادلة الانحدار ومعرفة أكثر متغير له دلائة إلهائة إحصائية

\begin{tabular}{|c|c|c|c|}
\hline \multirow{2}{*}{ Sig } & $\bar{T}$ & $\bar{\beta}$ & المتغير المستقلّل \\
\hline & $T \Gamma, \cdot \leqslant \Lambda$ & Y, \{ 7Y & أَتَّابت \\
\hline 0.00 & $0, \cdot \lambda r$ & $2, ., 17 Y$ & الوعى البيئي للمستهلكين \\
\hline 0.01 & 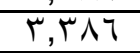 & $\cdot, 1 \Gamma$ & القوانين والَسياسات البيائية \\
\hline 0.028 & $r, Y, O$ & $\cdot, \mathrm{VO}$ & ضغوط المستثمرين والمساهمين \\
\hline 0.763 & -- & -- & حاجة البنوك لمعلومات بيئية \\
\hline 0.050 & $1,9 \vee \varepsilon$ &., 17 & ضغوط الجماعات البيائية \\
\hline
\end{tabular}

معاملات نموذج الانحدار

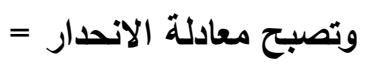

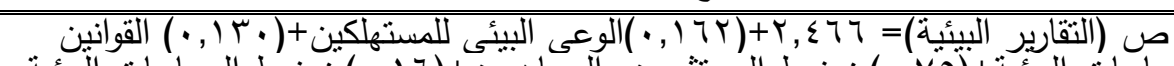

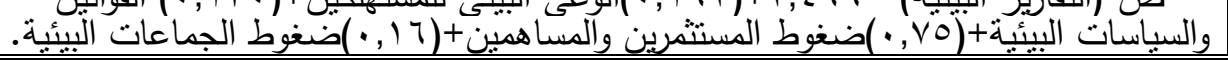

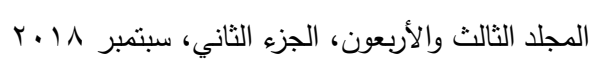


ويتضح ان المتغيرات المستقلة التى لها أكثر دلالة إحصائية على المتغير التابع هى (الوعى البيئى للمستهلكين)، (القوانين والسياسات البيئية)، (ضغوط المستثمرين والمساهمين)، (ضغوط الجماعات البيئية) ونم حذف المتغير المستقل (حاجة البنوك للمعلومات البيئية) لأن $. \operatorname{sig}=0.763>0.100$

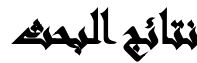

\section{أهم نتائج الاراسة النظرية:}

- تتطلب التتمية المستدامة تنبى مفهوم الأداء البيئى والأجتماعى بجانب الأداء المالى - إن ممارسات حوكمة الثركات الجيدة تفرض عناية خاصة ومسئولية من إدارة الثركة نحو

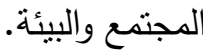

- المراجعة البيئية تعتبر جزء من نظام الإدارة البيئية - إن الإلنزامات البيئية من العناصر التى تتضمن خطر مرتفع، لذا فإن مراقب الحسابات يقوم يتوسيع نطاق عينته عند مراجعة هذا العنصر .

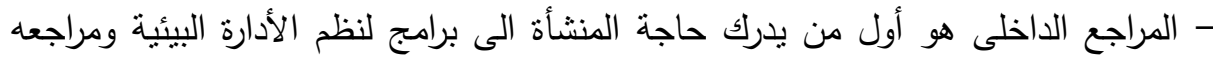

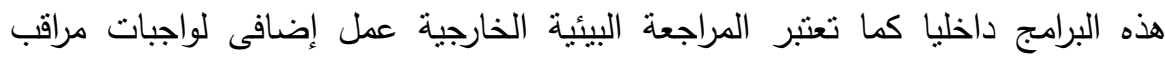
الحسابات فى أى شركة يتسبب نشاطها فى إحداث أثنار سلبية على البيئة. - يمكن الاستفادة من معايير المراجعة الدولية وتطويعها بما يخدم مجال المراجعة البيئية، وتقديم مساعدة عملية لمراقب الحسابات عند ممارسته للأحكام المهنية.

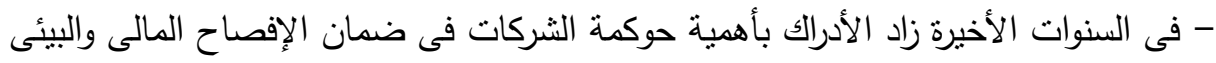
السليم وردع الإحتيال ويعد تعديل هياكل حوكمة الثركات خطوة هامة فى مواجهة تحديات

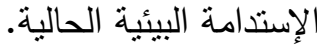

\section{نتائج الدراسة الميدانية}

- يوجد علاقة إحصائية ذات دلالة جوهرية بين آليات ومبادىء حوكمة الثركات والتى تتمثل فى (مبدأ الإفصاح والثفافية- حجم مجلس إدارة الثركة-إستقلالية مجلس الإدارة- ملكية أعضاء المجلس فى أسهم الثركة-لجان المراجعة) وجودة التقارير البيئية 
- يوجد علاقة إحصائية ذات دلالة جوهرية بين آليات حوكمة الشركات والتى تتمثل فى

(كفاءة الإدارة التنفيذية- لجان المراجعة - المراجعة الداخلية ) وفاعلية المراجعة البيئية. - يوجد علاقة إحصائية ذات دلالة جوهرية بين المراجعة البيئية ودوافع تطبيق الحوكمة البيئية فى الثركات (الوعى البيئى لدى المستهلكين- القوانين والسياسات التى نطالب بحماية

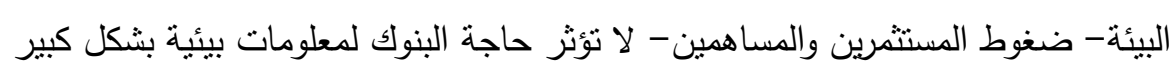
- لا تؤئز ضغوط الجماعات البيئية بشكل كبير) .

- يوجد علاقة إحصائية ذات دلالة جوهرية بين التقارير البيئية ودوافع تطبيق الحوكمة البيئية فى الثركات ( الوعى البيئى لدى المستهلكين- القوانين والسياسات التى نطالب بحماية

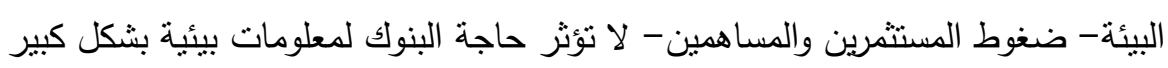

- ضغوط الجماعات البيئية).

\section{تموسيامت المهيد}

يوصى الباحث بالآتى: - مئى

- ضرورة إصدار الحكومات لقوانين وتشريعات جادة وصارمة تثعلق بحماية البيئة من الأثار السلبية الناتجة عن أنشطة الشركات.

- عقد مؤتمرات وندوات علمية يدعى إليها الخبراء والمتخصصين في هذاته التهات المجال .

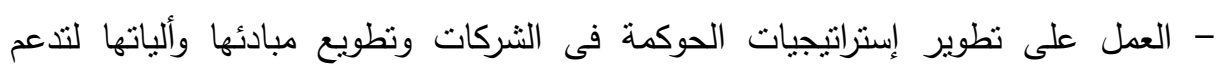

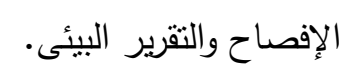

- ضرورة قيام جمعية المحاسبين والمراجعيين المصرية بإصدار معايير للمحاسبة والمراجعة خاصة بالأداء البيئى.

- مساهمة كلا من الجهاز المركزى للمحاسبات بصفته جهة رقابية عليا ومكاتب المحاسبة والمراجعة الصغيرة والكبيرة فى تفعيل دور مراقبى الحسابات عند مراجعة الأداء البيئى.

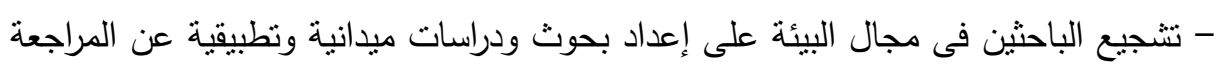
البيئية والأثار الحوكمية عليها.

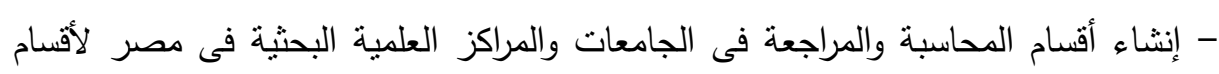
جديدة (للمحاسبة والمراجعة البيئية).

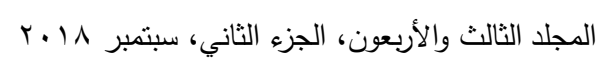


- محاولة الأستفادة من معايير المراجعة الدولية وتطويعها بما يخدم مجال المراجعة البيئية.

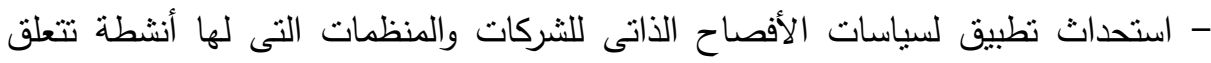
بالبيئة وذللك بإنشاء بوابة مركزية (للأفصاح الأكترونى ) على شبكة الأنترنت.

\section{المرالئ2}

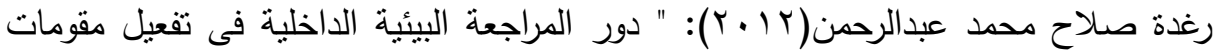

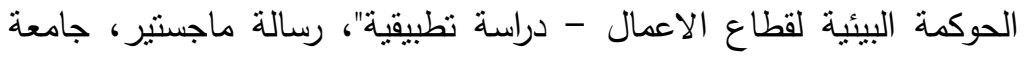
القاهرة

على عبداله أحمد الجبرى: المراجعة الداخلية ومراجعة الأداء البيئى - دراسة تحليلية، المجلة

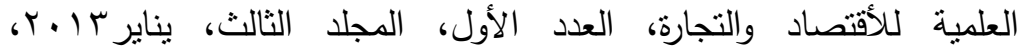

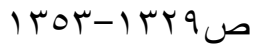

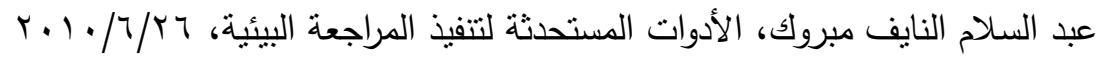

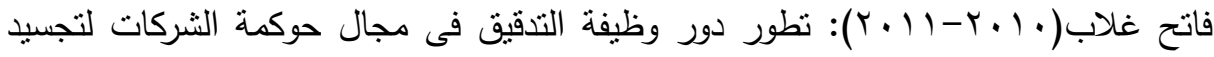
مبادىء ومعايير التتمية المستدامة، جامعة فرحات عباس سطيف بالجزائر رسالة ماجستير

Ahlberg Matthias (may 2014): "the sustainability movement (the institutionalization of sustainability in organizations "unpublished theis" ,Gothenburg university,.

Dvorakova Dana ,"Environmenatl information in financial statements"new comprehensive income",journal of competitiveness, 1/2009,p.p 21-31.

Department of Environmental Affairs and Tourism (DEAT) Environmental Auditing, Integrated Environmental Management, Information Series 14, (2004), Pretoria, p .5.

Lenciu,Lonel-Alin; Popa,Irlmie Emil; Nicoleta Maria,"Environmental Reporting and good practice of corporate governance:petroleum industry case study", sciverse sciencedirect,procedia economics and finance 3(2012)961967. 
أوركبد أحمد مدحت محمد وآخرون

Todea, Nicola (2011): Cornelia Stanciu, Ionela; Joldos (Udrea), Ana Maria," Environmental auditing ,Apossible source of information for financial auditors", Annales Universitaties Apulensis Series Oeconmica ,13(1),.

Kutz c05.tex, Industrial waste auditing, V1 .22/12/2006 p125.

\title{
A SUGGESTED FRAMEWORK FOR AUDITING THE ENVIRONMENTAL REPORTS IN LIGHT OF CORPORATE GOVERNANCE (FIELD STUDY)
}

\author{
Ahmed, Orkeed, A. M. M. K.. ${ }^{(1)}$;Tolba, A. I. ${ }^{(2)}$ \\ and Abdel El- Bar, A. H. ${ }^{(2)}$ \\ 1) Accountability State Authority 2) Faculty of Commerce, Ain Shams \\ University
}

\begin{abstract}
The emergence of the concept of sustainable development has led companies to become more aware of the importance of disclosing the environmental and social performance aspects of their activities .Therefore ,companies prepare special reports or parts of their annual reports to disclose their environmental and social performance, in order to enhance the credibility of these reports,companies present their reports to external auditors to approve it.

The main objective of the research is to evaluate the profession of auditing the environmental reports as a regulatory tool in the field of corporate governance.

The research draws attention from the growing interest in sustainable development, the new trend to address the important environmental issues in the preparation of financial reports ,the audit profession recognition of the importance of disclosing the environmental issues, the increasing demand for expanding the role of the Auditor to include the environmental performance, the good

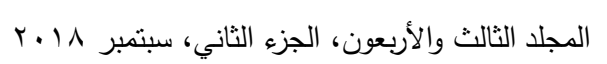


corporate governance will be achieved through the establishment of the safety and environmental responsibility committees that monitor the environmental impact within the company, the confirmation of many studies on the need to establish an integrated framework of the concept of corporate governance.

The study population was represented by the Accountability state Authority, the data were collected through a survey questionnaire ,the sample consisted of 233valid forms collected from 14 Accountability state Authority accounts,All hypotheses were tested and all hypotheses were accepted.

The most important results of the study's analysis are the principles and mechanisms of corporate governance, which are represented in (the principle of disclosure and transparency-independence and size of the board of directors -the ownership of the board members...etc) positively affect the quality of environmental reports and the effectiveness of environmental auditing, and the motives of applying environmental governance in companies, which are(consumer awareness-investor pressures-the need of banks for environmental information....etc )positively affect the quality of environmental reports and the effectiveness of environmental auditing, but to varying degrees.

\section{Recommendations}

-The need for governments to enact serious and strict laws and regulations relating to the protection of the environment from the negative effects resulting from the activities of companies

- Scientific conferences and symposia for experts and specialists in this field

- Developing corporate governance strategies and adapting their principles and mechanisms to support disclosure and environmental reporting

-The need for the Egyptian Association of Accountants and Auditors to issue accounting and auditing standards for environmental performance

-The contribution of the accountability state authority in its capacity as a supreme regulatory body and the small and large accounting and

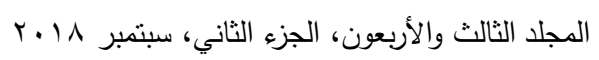


auditing offices in activating the role of the auditors in auditing the environmental performance

-To encourage researchers in the field of the environment to prepare research and field studies and applied on environmental auditing and the effects of governance

-Establishing accounting and auditing departments in universities and scientific research centers in Egypt for new departments (for accounting and environmental auditing(

-Trying to benefit from the international auditing standards and adapt them to serve the field of environmental auditing

-Develop an application of self-disclosure policies for companies and organizations that have activities related to the environment by establishing a central portal (for electronic disclosure) on the Internet

-Enhancing the role of the media in spreading awareness among the accounting and auditing companies, setting up media campaigns to raise the awareness of society about the importance of preserving the environment and forming environmental groups to pressure companies that cause pollution to the environment 